\title{
Prevalence and Genotype Analysis of Blastocystis hominis in Iran: A Systematic Review and Meta-Analysis
}

\author{
Ebrahim Badparva, ${ }^{1}$ Behrouz Ezatpour, ${ }^{2,}$ Hossein Mahmoudvand, ${ }^{1}$ Masoud Behzadifar, ${ }^{3}$ Meysam \\ Behzadifar, $^{4}$ and Farnaz Kheirandish ${ }^{1}$ \\ ${ }^{1}$ Department of Medical Parasitology and Mycology, School of Medicine, Lorestan University of Medical Sciences, Khorramabad, IR Iran \\ ${ }^{2}$ Razi Herbal Medicines Research Center, Department of Medical Parasitology and Mycology, Lorestan University of Medical Sciences, Khorramabad, IR Iran \\ ${ }^{3}$ Health Management and Economics Research Center, Iran University of Medical Sciences, Tehran, IR Iran \\ ${ }^{4}$ Department of Public Health, Faculty of Health and Nutrition, Lorestan University of Medical Sciences, Khorramabd, IR Iran \\ "Corresponding author: Behrouz Ezatpour, Razi Herbal Medicines Research Center, Department of Medical Parasitology and Mycology, Lorestan University of Medical Sciences, \\ Khorramabad, IR Iran. Tel: +98-6633204005, E-mail: bezatpour@gmail.com
}

Received 2016 January 26; Revised 2016 June 16; Accepted 2016 June 19.

\begin{abstract}
Context: Blastocystis hominis is a unicellular protozoan found commonly in the intestinal tract of humans and many other animals with multiple subtypes, which tend to be specific to the host. We aimed to apply a meta-analysis for studies of protozoan pathogens in order to obtain a general overview of the prevalence and genotype analysis of Blastocystis spp. in Iran.

Evidence Acquisition: International electronic databases such as PubMed, Scopus, ISI Web of Science, Ovid, Google scholar, and national databases including SID, Iranmedex and Magiran were searched from 2003 to 2015 for studies that reported the prevalence of $B$. hominis in Iran. We calculated prevalence estimates with $95 \%$ CIs and assessed heterogeneity between studies using the I2 statistic and the Cochran Q test.

Results: We included 40 eligible studies in this review. The pooled prevalence of Blastocystis hominis was 3\% (95\% CI: 3 - 3).

Conclusions: Unlike the world, a ST5 subtype of human cases is common and the reservoir seems to be cattle. ST2 has been found in birds in Iran. Further studies are needed to confirm these important findings and to clarify the possible pathogenesis and reveal whether this is an exception or the rule.
\end{abstract}

Keywords: Blastocystis hominis, Subtype, Epidemiology, Iran

\section{Context}

Blastocystis spp. is a unicellular, obligate anaerobic protozoan, which is observed in the human intestinal tract, and colonizes many vertebrates and invertebrates (1), which are considered as a reservoir host for humans (2). Over the past 100 years, Blastocystis spp. has had a varied taxonomic history, being described as a non-pathogenic yeast. In the 1970s to 1980s its biological and clinical properties were considered for the first time $(3,4)$. Despite a century has passed since its detection, only four morphological forms (cyst, granular, Vacuolar and amoeboid) and two transient stages (multi vacuolar and vacuolar) were detected, and there are many unknowns about it (5-7). Although many researchers have given credit to Blastocystis spp. as a pathogen $(3,8)$ and attributed symptoms such as abdominal pain, diarrhea, constipation, fatigue, vomiting, headaches, skin rash, joint pain and psychiatric illness to it (9-11), yet there is still much debate about the pathogenicity of this protozoa in humans. Many studies have verified water resistant thin-walled cysts (responsible for autoinfection) and water resistant thick-walled cysts in feces and contaminated water and food (12); this explains the importance of the oral-fecal route as the main form of transmission of Blastocystis spp. in human-human or animal- human transmission. Zoonotic transmission was reported in animals such as chicken, horse and pig $(6,12,13)$. Blasto- cystis was recommended as one of the indicators of fecal contamination of source water by the World Health Organization (14). Based on morphological criteria, Blastocystis spp. isolates from animals and humans are almost indiscernible (3).

Based on differences in some properties such as host source, morphology, in vitro culture characteristics and/or phylogenetic analysis of SSU rRNA gene sequences of Blastocystis isolates, 17 subtypes (STs) from different mammalian, avian and amphibian species have been described, with subtype 1- 9 being found in humans (15-17). Seven standardized ST-specific STS primers $\left(\mathrm{ST}_{1-7}\right)$ have been used in epidemiological studies and other studies on relevant factors such as hosts, transmission and zoonoses $(15,17)$. Only four of them are prevalent $\left(\mathrm{ST}_{1}, \mathrm{ST}_{2}, \mathrm{ST}_{3}\right.$ and $\left.\mathrm{ST}_{4}\right)$ and show around $90 \%$ of the subtyped isolates. The majority of infections with Blastocystis spp. in humans are attributable to $\mathrm{ST}_{3}$, but infections with $\mathrm{ST}_{1}, \mathrm{ST}_{2}$ and $\mathrm{ST}_{4}$ are also frequent (1820). $\mathrm{ST}_{5}$ to $\mathrm{ST}_{9}$ have been isolated only rarely from humans $(2,21,22)$ while $\mathrm{ST}_{10}-\mathrm{ST}_{17}$ have not been found in humans (23-25). Blastocystis hominis is a suggested name for the organism isolated from human fecal by Brumpt (26). Various studies have demonstrated that humans with close animal contact (food and animal handlers) have a higher risk of infection with Blastocystis spp. (2, 3, 27, 28).

Although $B$. hominis was obtained from many studies 
on fecal samples (29), no review study has been done on prevalence and genotype analysis in Iran. Against this background, we performed a systematic review of the literature to identify the situation of this parasite in Iran. This study could help policy makers with an evidence-based summary of the primary literature on decisions.

\section{Evidence Acquisition}

\subsection{Search Strategy}

PubMed, Scopus, ISI Web of Science, Ovid, Google scholar, and national databases including SID, Iranmedex and Magiran were searched for studies in English and Persian language to identify prevalence B. hominis in Iran, until July 2015. The following search terms were used: "Blastocystis hominis" OR "Blastocystis" AND "prevalence" OR “epidemiology” AND "Iran”. English and Persian language articles were recognized by two independent researchers and the appropriate studies were carefully chosen for evaluation.

\subsection{Inclusion Criteria and Trial Selection}

We included population-based studies that reported the prevalence of $B$. hominis among the Iranian population, including case reports, case-series, and letter to editor while non-Iranian studies were excluded.

\subsection{Quality Assessment}

The quality of the retrieved studies was assessed using the STROBE (30).

\subsection{Data Extraction}

Two of the authors independently extracted data from the selected papers and disagreements were resolved by discussions between the authors. The extracted information from the studies included the first author, year of publication, sample size, the study population, prevalence of intestinal parasites, prevalence of studies, and study region. Four hundred and thirteen potentially related studies were identified from the initial searches, but only 40 studies were included in the meta-analysis. The article selection procedure is shown in Figure 1.

\subsection{Statistical Analysis}

We estimated prevalence using the meta-analysis random effect methods model (using the DerSimonian and Laird method) with confidence interval heterogeneity between studies assessed by using I square and Cochran's Q tests. Publication bias was examined by egger test and funnel plot. $\mathrm{P}<0.05$ was considered significant. To ensure the robustness of the results, a sensitivity analysis was performed. This was done to demonstrate the impact of any study done on the final result. To this end, a study came out and then a sensitivity analysis was performed in its absence. The analyses were conducted with STATA software, version 12 (Produced by StataCorp, USA) (9, 31-69).

\section{Results}

In this meta-analysis, 40 studies published between 2003 and 2015 were identified and entered into the final analysis, to measure the prevalence of $B$. hominisis among symptomatic patients and asymptomatic individuals. Quality assessment showed that 25 articles (62.5\%) had good quality, eight articles (20\%) had medium quality and seven articles (18.5\%) had poor quality. It seemed that in the reported results, publication bias occurred $(\mathrm{P}=0.001)$. The total prevalence of $B$. hominisis was 3\% (95\% CI, 3 - 3). The results showed that this relationship was not statistically significant; however, $B$. hominisis prevalence rate decreased during this period. The results showed that prevalence of blastocystosis had a decreasing trend in Iran. The performed studies are presented in Tables 1 and 2 along with three illustrations.

Blastocystis hominisis is presumably the most common protozoan found in human faecal samples of both symptomatic patients and asymptomatic individuals worldwide. Blastocystis infection rate has a prevalence ranging from $1.5 \%$ to $20 \%$ in industrialized countries, whereas in developing countries the rate is $30 \%$ to $50 \%$ (70). Blastocystis spp. is now recognized as an emerging zoonosis by many researchers (12). Regarding the pathogenic potential of Blastocystis, it was widely debated in the literature during the last two decades because the organism can be found in both symptomatic and asymptomatic patients. Our study demonstrated that the prevalence of Blastocystis spp. rate in Iran was 3\% between 2003 and 2015. The prevalence of $B$. hominis in the USA has decreased significantly over the last two decades from 2.6 to $23 \%$, which may be epidemiologically significant; and increasing prevalence rates were also noted in the recent years. This prevalence rate was in line with other studies from Switzerland (16.7\% - 19.0\%) (71) and Taiwan (20.4) (72), yet the rate reported from Chile (61.8\%) (73) and Albanian (54.5\%)(74) was considerably higher than our results.

In epidemiological studies, genomic researches are more advantageous than other methods; because, firstly they are more sensitive and able to detect all the morphological forms, live and dead microorganisms (22), secondly, these studies are the only way to identify the subtypes of microorganisms $(2,15,27)$ and thirdly, they can act as a complement to previous studies. Moreover, diagnoses of 
Table 1. The Incidence and Prevalence of the Intestinal Parasite Blastocystis Relative to Other Parasites and Year of Distribution

\begin{tabular}{|c|c|c|c|c|c|c|}
\hline Reference & Region & Number of Stool Samples & The Study Population & Prevalence of Intestinal Parasites & Prevalence of Blastocystis & Level \\
\hline (Arani et al. 2008) & Tehran & 4371 & Patients & 10.7 & 54.5 & First \\
\hline (Ebadi et al. 2007) & Yazd & 1500 & Children $\leq 14$ years & 8.5 & 41.3 & First \\
\hline (Daryani et al. 2006) & Northwest of Iran & 1070 & School children & 52 & 28.2 & First \\
\hline (Kuzehkanani et al. 2011) & Bandar Abbas & 656 & Rural inhabitants & 48.8 & 25.5 & First \\
\hline (Neghab et al. 2006) & Shiraz & 39 & Food handlers & 59.4 & 25.4 & First \\
\hline (Khalili et al. 2014) & ShahreKord & 160 & Hospitalized children & 36.25 & 23 & First \\
\hline (Davari et al. 2013) & Ardabil & 216 & Mental disabilities & 44 & 19 & First \\
\hline (Rostami et al. 2012) & Gorgan & 800 & School children & 28.8 & 15.2 & First \\
\hline (Akhlaghi et al. 2009) & Tehran & 1000 & Patients & 21.2 & 12.8 & First \\
\hline (Sabati et al. 2004) & Abu Musa & 120 & School children & 27.5 & 12.5 & First \\
\hline (Jafari et al. 2014) & Isfahan & 652 & Patients & 10.42 & 7.36 & First \\
\hline (Asmar et al. 2014) & Bandar Anzali & 700 & Inhabitants & 15.1 & 6.4 & First \\
\hline (Meamar et al. 2007) & Tehran & 781 & HIV+/AIDS patients & 11.4 & 6.1 & First \\
\hline (Rostami et al. 2007) & Iran & 706 & Renal transplant recipients & 4.5 & 1.7 & First \\
\hline (Falahi et al. 2007) & Khorramabad & 306 & HIV+/AIDS patients & 22.5 & 19.2 & Second \\
\hline (Asgari et al. 2003) & Eslamshahr & 1535 & Inhabitants & 53.2 & 16.5 & Second \\
\hline (Jafari et al. 2014) & Hamedan & 228 & Inhabitants & 35.1 & 14 & Second \\
\hline (Daryani et al.2005) & Ardabil & 1070 & Primary school students & 27.7 & 10.2 & Second \\
\hline (Kia et al. 2008) & Mazandaran & 855 & Rural inhabitants & 25 & 9.8 & Second \\
\hline (Taherkhani et al. 2007) & Kernanshah & 75 & HIV+/AIDS patients & 36 & 8 & Second \\
\hline (Hazrati Tappeh et al. 2011) & Urmia & 101 & patients & 19.8 & 5.9 & Second \\
\hline (Badparva et al. 2012) & Lorestan & 2838 & Inhabitants & 16.5 & 5 & Second \\
\hline (Zali et al. 2004) & Iran & 206 & HIV+/AIDS patients & 18.4 & 4.4 & Second \\
\hline (Hooshyar, Bagherian et al.) & Kashan & 6348 & Patients & 7.6 & 2.5 & Second \\
\hline (Ebadi et al. 2008) & Yazd & 13388 & Patients & 8.6 & 15.51 & Third \\
\hline (Khosrow et al. 2011) & Western Azerbaijan & 405 & Primary school students & 42.5 & 13.3 & Third \\
\hline (Nasiri et al. 2009) & Karaj & 13915 & Inhabitants & 4.7 & 8 & Third \\
\hline (Gholami et al. 2005) & Babol & 181 & Cattle breeders & 31.5 & 6.9 & Third \\
\hline (Mowlavi et al. 2008) & Khuzestan & 1494 & Nomads & 25.36 & 2.4 & Third \\
\hline (Haghighi et al. 2009) & Zahedan & 1562 & Patients & 27.3 & 2.2 & Third \\
\hline (Kheirandish et al. 2011) & Khorramabad & 816 & Bakery workers & 11.9 & 2.1 & Third \\
\hline (Kheirandish et al. 2014) & Khorramabad & 210 & Food handlers & 9 & 1.4 & Third \\
\hline (Sadeghi et al. 2015) & Qazvin & 5739 & Patients & 5.92 & 0.94 & Third \\
\hline (Mafi et al. 2014) & Iran & 4200 & Patients & 2.4 & 0.5 & Third \\
\hline (Tappeh et al. 2010) & Urmia & 225 & Mentally disabled & 20.4 & 4 & Fourth \\
\hline (Heidari et al. 2003) & Damghan & 461 & Children $\leq 6$ years & 68.1 & 4.8 & Seventh \\
\hline (Fallah et al. 2014) & Tabriz & 558 & 2-20 years & - & 26.17 & - \\
\hline (Sardarian et al. 2013) & Hamedan & 250 & Patients & - & 16.4 & - \\
\hline (Moosavi et al. 2012) & Tehran & 420 & Patients & - & 15.2 & - \\
\hline (Badparva et al. 2014) & Khorramabad & 511 & Patients & - & 6.5 & - \\
\hline Total & Iran & 61000 & - & 24.94 & 12.52 & - \\
\hline
\end{tabular}

Table 2. The Relative Distribution of Blastocystis spp. Subtypes (1 - 7) Infecting Humans in Different Geographic Regions of Iran, Based on Four Studies

\begin{tabular}{|c|c|c|c|c|c|c|c|c|c|}
\hline Provience [Reference] & Number of Stool Samples & Subtype 1 & Subtype 2 & Subtype 3 & Subtype 4 & Subtype 5 & Subtype 6 & Subtype 7 & Unknown Subtype/Mixed Subtype \\
\hline Tehran (Moosavi, 2012) & 174 & $48(27.5 \%)$ & $7(4 \%)$ & $53(30.5 \%)$ & . & $33(19 \%)$ & . & . & $33(19 \%)$ \\
\hline (Lorestan((Badparva,2014) & 30 & . & $4(13.3 \%)$ & $17(56 \%)$ & . & $6(20 \%)$ & . & . & $3(10 \%)$ \\
\hline Hamadan (Sardarian, 2013) & 41 & $23(56.1 \%)$ & $3(7.3 \%)$ & $9(23 \%)$ & . & . & . & . & $6(14.4 \%)$ \\
\hline Total & $285(100 \%)$ & $91(31.9 \%)$ & $14(4.9 \%)$ & $95(33.3 \%)$ & . & $43(15.1 \%)$ & . & . & $42(14.8 \%)$ \\
\hline
\end{tabular}




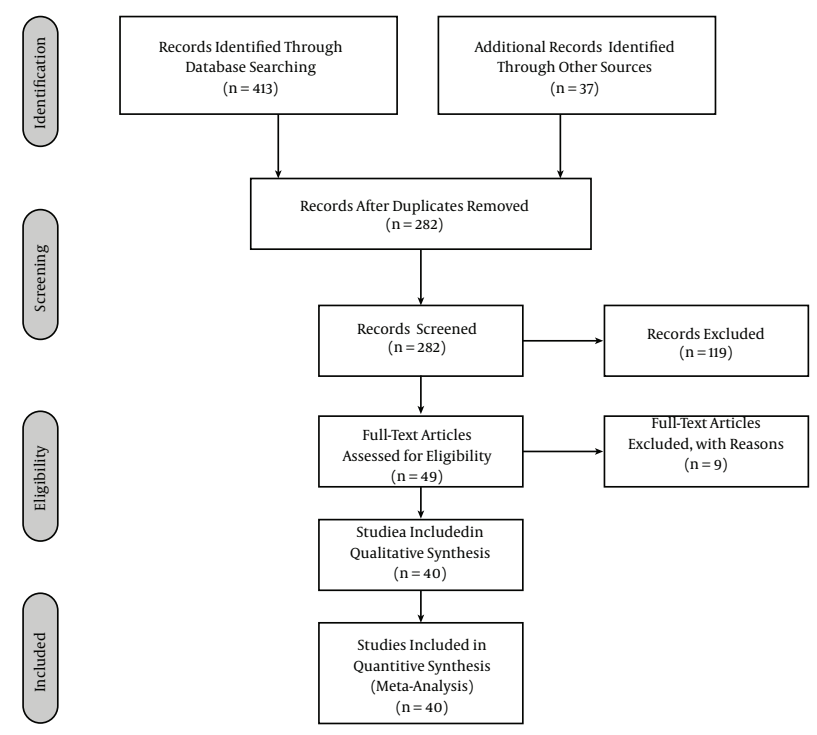

Figure 1. Study Chart

subtypes that in special conditions tend to specific host only perform in genomic studies $(2,15,17,27,28)$. To the best of our knowledge, this is the first review study on epidemiology of Blastocystis spp. in Iran. In this study, we reviewed all studies focusing on the prevalence and significance of intestinal parasite infections among different age groups, geographical, continental and cultural conditions in Iran in the last decade. In addition, we also investigated a few studies about the genomic properties of Blastocystis that were done in this region. The results showed that the average prevalence rate of $B$. hominis by common diagnostic methods (wet mount, concentration assays and in some cases staining methods) is $12.25 \%$. Previous studies demonstrated that this rate in industrialized countries is 1.5 to $20 \%$ $(70,75)$, while it is $30 \%-50 \%$ in developing countries (75). In $38.9 \%$ of studies, which investigated parasitic infection, B. hominis was the most common intestinal parasite and in $94.3 \%$, it was the first to third most common parasite. Accordingly, the prevalence rate of $B$. hominis is higher than other intestinal parasites in Iran. In the USA, the prevalence of this protozoan increased from 2.6 to $23 \%$ in the recent 20 years. In some states it is known as an emerging parasite and a hygiene warning $(12,76,77)$. The interesting point is that, despite hygiene promotion, the prevalence of parasites, which have been transmitted in similar ways, has decreased (32). This may be due to unknown transmission pathways and it needs more studies to clarify the matter. There has been less attention to $B$. hominis in the diagnostic and training field in Iran and clinicians do not believe in pathogenicity and its treatment that may play a role in increasing its prevalence.

Result of only three genomic studies that were performed in Iran $(36,60,64)$ are similar to many studies performed in other regions of the world that have reported ST3 as the most common subtype of $B$. hominis in the world (7\% - 92\%) $(78,79)$. Some researchers have attributed ST3 to urticaria, HIV and cancer (80). However, 13.3\% of bovine Blastocystis subtypes are ST3 in Iran (81) that may influence the dissemination and transmission between the two hosts. Although, the second and third subtypes were ST1 and ST5, they have not been reported in all studies in Iran. Furthermore, ST1 is known as a pathogenic subtype in patients with gastrointestinal symptoms (20, 78, 79). Mostly, ST5 has been found in cattle and pigs (2) and it has been reported in some regions such as Sweden (82). Since 98\% of the Iranian population are Muslims and pork is rarely consumed because it goes against Islamic law, and on the other hand, $60 \%$ of bovine subtypes is ST3 in Iran (81), it is inferred that cattle can be the host of ST5 in the region.

\section{Conclusions}

Another subtype, which was found in this study, was ST2 that is considered as the second most common subtype around the world (27), but the relationship between human and monkeys is infrequent in Iran. Since geographical distribution of ST2 is similar to ST3 in Iran, it is likely that their ways of transmission is very similar. Some conflicting reports have been published on the pathogenesis of ST2. There are several studies verifying its high degree 
Figure 2. Forest Plots for Random Effects Meta-Analysis

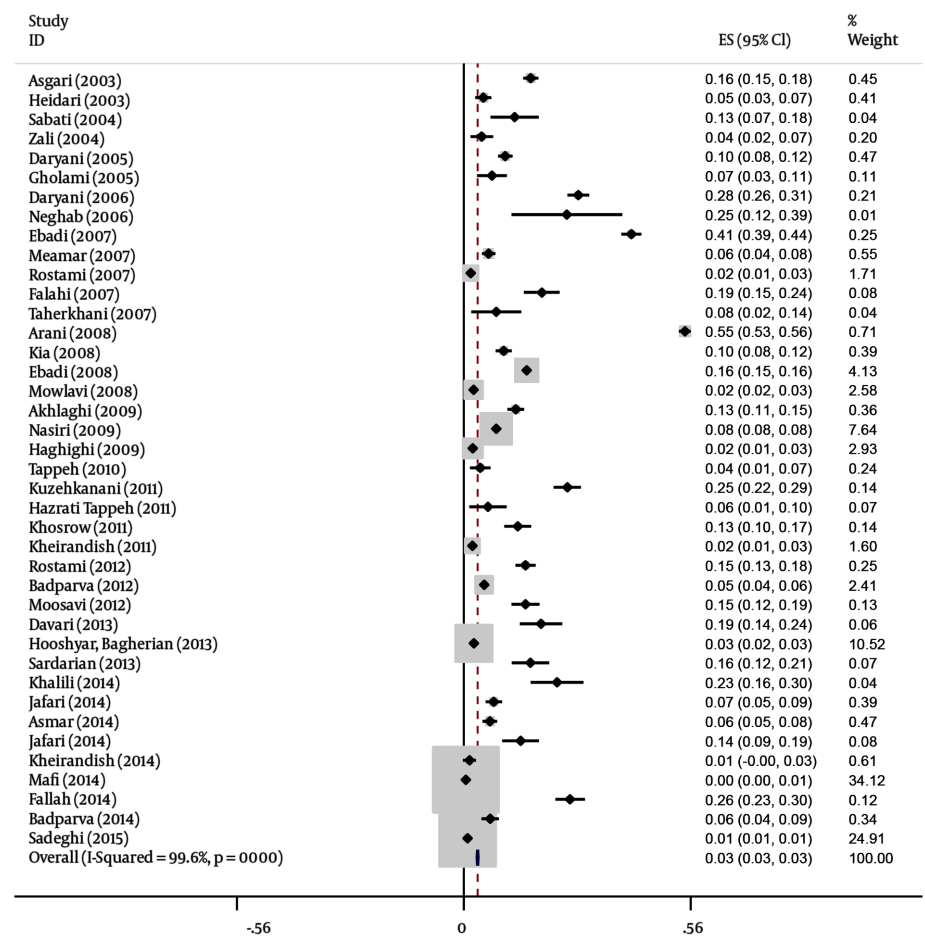

CI indicates confidence interval.

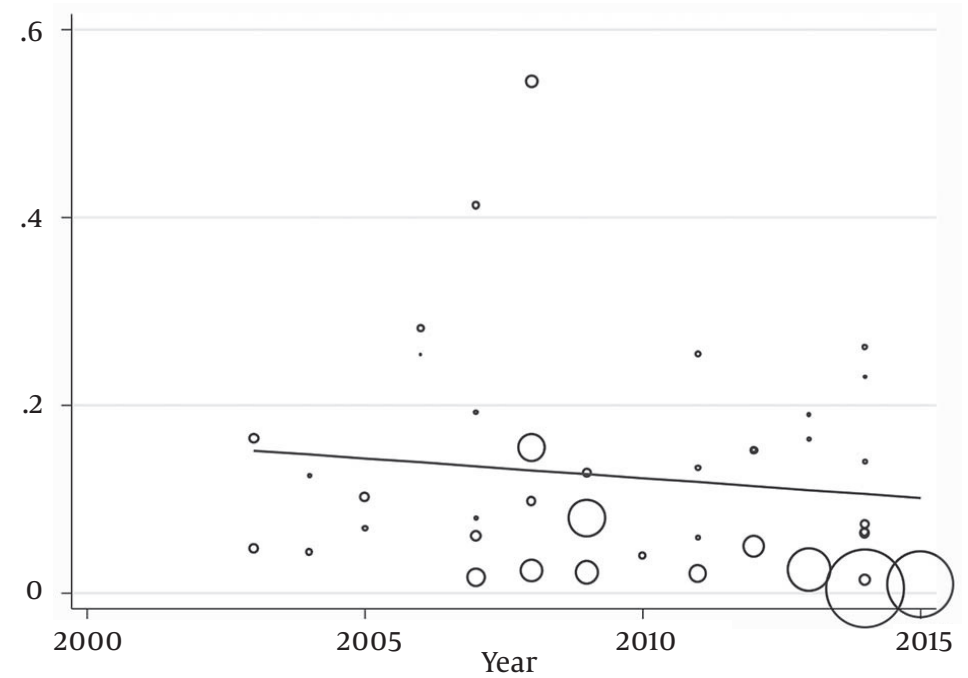

Figure 3. Meta Regression Diagram of Blastocystosis Indicating That Prevalence is Increasing With Year; The Larger Diameter of the Circle the Higher Prevalence of Parasites

of infectivity (19), whereas some others have not confirmed the infectivity of ST2 (17). Although, ST6 and ST7 are known as the bird subtypes (83), in a study on birds, ST2 was also reported as a bird subtype (84). Future studies should reveal whether this is an exception or the rule. It should be pointed out that in the study conducted on birds of Khor- 


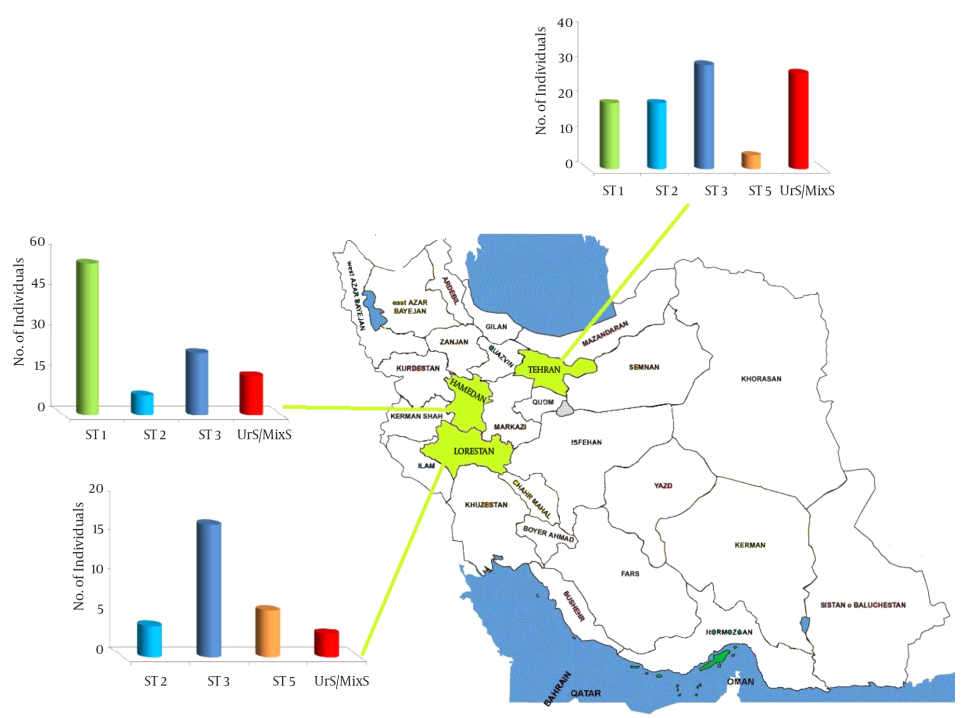

Figure 4. The Relative Distribution of Blastocystis spp. Subtypes Infecting Humans in Different Geographic Regions of Iran

Figure 5. Sensitivity Analysis

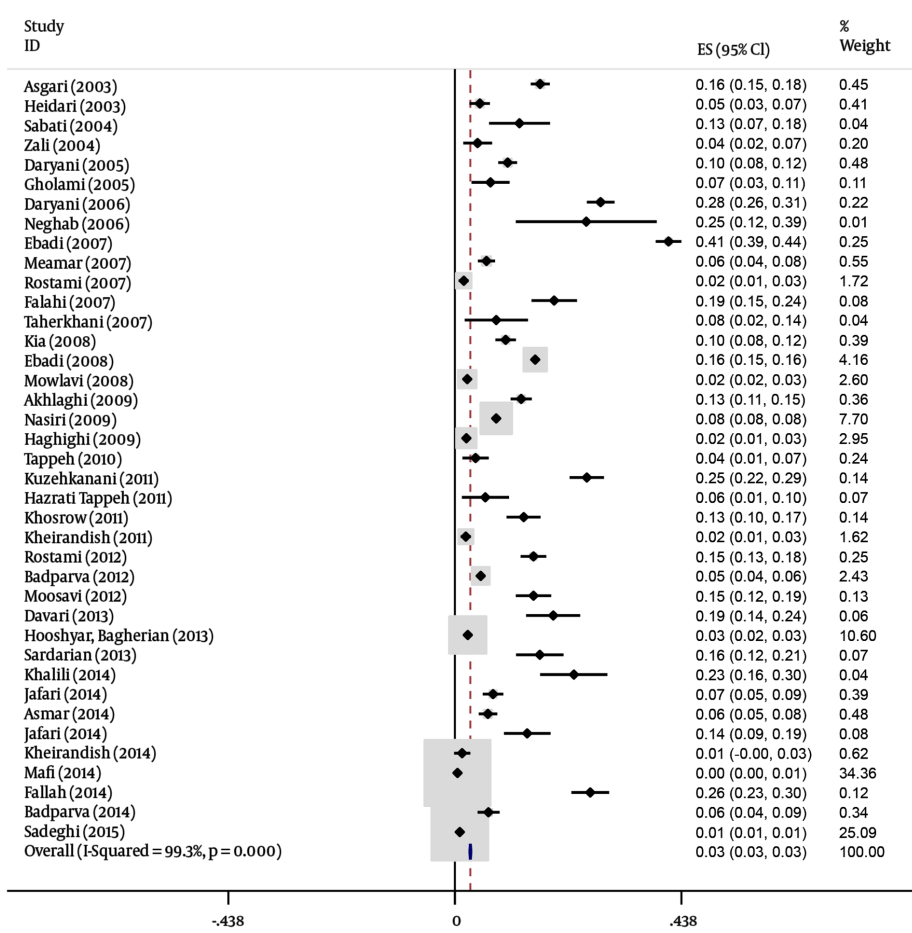

To ensure strong results, we removed one of the studies to analyze the sensitivity. When the Asghari et al. study (31) was excluded the overall prevalence did not change.

ramabad, Blastocystis spp. was not observed (85).

Although Blastocystis genomic studies on humans and animals are common in many regions of the world, these studies are rare in Iran and belong to the recent years 
and limited to some specific areas in the country $(36,60$, $64)$. We hope that similar investigations will be expanded in the future to collect more useful information to help health policy makers in this region to better understand the prevalence and pattern of the disease.

\section{Acknowledgments}

This study was financially supported by the Deputy of Research and Technology Affairs, Lorestan University of Medical Sciences.

\section{Footnote}

Conflict of Interest: None of the authors had conflict of interest.

\section{References}

1. Yoshikawa H, Wu Z, Howe J, Hashimoto T, Geok-Choo N, Tan KS. Ultrastructural and phylogenetic studies on Blastocystis isolates from cockroaches. J Eukaryot Microbiol. 2007;54(1):33-7. doi: 10.1111/j.15507408.2006.00141.x. [PubMed: 17300516].

2. Yan Y, Su S, Ye J, Lai X, Lai R, Liao H, et al. Blastocystis sp. subtype 5: a possibly zoonotic genotype. Parasitol Res. 2007;101(6):1527-32. doi: 10.1007/s00436-007-0672-y. [PubMed: 17665214].

3. Tan KS. New insights on classification, identification, and clinical relevance of Blastocystis spp. Clin Microbiol Rev. 2008;21(4):639-65. doi: 10.1128/CMR.00022-08. [PubMed:18854485].

4. Zierdt CH. Blastocystis hominis-past and future. Clin Microbiol Rev. 1991;4(1):61-79. [PubMed: 2004348].

5. Dunn LA, Boreham PF, Stenzel DJ. Ultrastructural variation of Blastocystis hominis stocks in culture. Int J Parasitol. 1989;19(1):43-56. [PubMed: 2707962].

6. Singh M, Suresh K, Ho LC, Ng GC, Yap EH. Elucidation of the life cycle of the intestinal protozoan Blastocystis hominis. Parasitol Res. 1995;81(5):446-50. [PubMed: 7501648].

7. Tan TC, Suresh KG. Evidence of plasmotomy in Blastocystis hominis. Parasitol Res. 2007;101(6):1521-5. doi: 10.1007/s00436-007-0670-0. [PubMed: 17701428].

8. Andiran N, Acikgoz ZC, Turkay S, Andiran F. Blastocystis hominisan emerging and imitating cause of acute abdomen in children. $J$ Pediatr Surg. 2006;41(8):1489-91. doi: 10.1016/j.jpedsurg.2006.04.037. [PubMed: 16863863].

9. Daryani N, Barmaki GH, Ettehad M, Sharif MH, Dehghan A. A crosssectional study of Blastocystis hominis in primary school children, Northwest Iran. Inter J Trop Med. 2006;1:53-7.

10. Jones MS, Whipps CM, Ganac RD, Hudson NR, Boorom K. Association of Blastocystis subtype 3 and 1 with patients from an Oregon community presenting with chronic gastrointestinal illness. Parasitol Res. 2009;104(2):341-5. doi: 10.1007/s00436-008-1198-7. [PubMed: 18923844].

11. Boorom KF, Smith H, Nimri L, Viscogliosi E, Spanakos G, Parkar $\mathrm{U}$, et al. Oh my aching gut: irritable bowel syndrome, Blastocystis, and asymptomatic infection. Parasit Vectors. 2008;1(1):40. doi: 10.1186/1756-3305-1-40. [PubMed: 18937874].

12. Basak S, Rajurkar MN, Mallick SK. Detection of Blastocystis hominis: a controversial human pathogen. Parasitol Res. 2014;113(1):261-5. doi: 10.1007/s00436-013-3652-4. [PubMed: 24169810].
13. Yoshikawa H, Yoshida K, Nakajima A, Yamanari K, Iwatani S, Kimata I. Fecal-oral transmission of the cyst form of Blastocystis hominis in rats. Parasitol Res. 2004;94(6):391-6. doi: 10.1007/s00436-004-1230-5. [PubMed: 15480786].

14. WHO. . Guidelines for drinking - water quality. 3 ed. Geneva: World Health Organization; 2008.

15. Stensvold CR, Suresh GK, Tan KS, Thompson RC, Traub RJ, Viscogliosi E, et al. Terminology for Blastocystis subtypes-a consensus. Trends Parasitol. 2007;23(3):93-6. doi: 10.1016/j.pt.2007.01.004. [PubMed: 17241816].

16. Roberts T, Stark D, Harkness J, Ellis J. Update on the pathogenic potential and treatment options for Blastocystis sp. Gut Pathog. 2014;6:17. doi: 10.1186/1757-4749-6-17. [PubMed: 24883113].

17. Yoshikawa H, Wu Z, Kimata I, Iseki M, Ali IK, Hossain MB, et al. Polymerase chain reaction-based genotype classification among human Blastocystis hominis populations isolated from different countries. Parasitol Res. 2004;92(1):22-9. doi: 10.1007/s00436-003-0995-2. [PubMed: 14598169].

18. Abdulsalam AM, Ithoi I, Al-Mekhlafi HM, Al-Mekhlafi AM, Ahmed A, Surin J. Subtype distribution of Blastocystis isolates in Sebha, Libya. PLoS One. 2013;8(12):ee84372. doi:10.1371/journal.pone.0084372. [PubMed: 24376805].

19. Ozyurt M, Kurt O, Molbak K, Nielsen HV, Haznedaroglu T, Stensvold CR. Molecular epidemiology of Blastocystis infections in Turkey. Parasitol Int. 2008;57(3):300-6. doi:10.1016/j.parint.2008.01.004. [PubMed: 18337161].

20. Souppart L, Sanciu G, Cian A, Wawrzyniak I, Delbac F, Capron M, et al. Molecular epidemiology of human Blastocystis isolates in France. Parasitol Res. 2009;105(2):413-21. doi: 10.1007/s00436-0091398-9. [PubMed: 19290540].

21. Meloni D, Sanciu G, Poirier P, El Alaoui H, Chabe M, Delhaes L, et al. Molecular subtyping of Blastocystis sp. isolates from symptomatic patients in Italy. Parasitol Res. 2011;109(3):613-9. doi: 10.1007/s00436011-2294-7. [PubMed: 21340563].

22. Li LH, Zhang XP, Lv S, Zhang L, Yoshikawa H, Wu Z, et al. Crosssectional surveys and subtype classification of human Blastocystis isolates from four epidemiological settings in China. Parasitol Res. 2007;102(1):83-90. doi: 10.1007/s00436-007-0727-0. [PubMed: 17912552].

23. Alfellani MA, Taner-Mulla D, Jacob AS, Imeede CA, Yoshikawa $\mathrm{H}$, Stensvold $\mathrm{CR}$, et al. Genetic diversity of blastocystis in livestock and zoo animals. Protist. 2013;164(4):497-509. doi: 10.1016/j.protis.2013.05.003. [PubMed: 23770574].

24. Roberts T, Stark D, Harkness J, Ellis J. Subtype distribution of Blastocystis isolates from a variety of animals from New South Wales, Australia. Vet Parasitol. 2013;196(1-2):85-9. doi:10.1016/j.vetpar.2013.01.011. [PubMed: 23398989].

25. Fayer R, Santin M, Macarisin D. Detection of concurrent infection of dairy cattle with Blastocystis, Cryptosporidium, Giardia, and Enterocytozoon by molecular and microscopic methods. Parasitol Res. 2012;111(3):1349-55. doi: 10.1007/s00436-012-2971-1. [PubMed: 22710524].

26. Denoeud F, Roussel M, Noel B, Wawrzyniak I, Da Silva C, Diogon M, et al. Genome sequence of the stramenopile Blastocystis, a human anaerobic parasite. Genome Biol. 2011;12(3):R29. doi:10.1186/gb-2011-123-r29. [PubMed: 21439036].

27. Yoshikawa H, Wu Z, Pandey K, Pandey BD, Sherchand JB, Yanagi T, et al. Molecular characterization of Blastocystis isolates from children and rhesus monkeys in Kathmandu, Nepal. Vet Parasitol. 2009;160(34):295-300. doi: 10.1016/j.vetpar.2008.11.029. [PubMed:19136214].

28. Rajah Salim H, Suresh Kumar G, Vellayan S, Mak JW, Khairul Anuar A, Init I, et al. Blastocystis in animal handlers. Parasitol Res. 1999;85(12):1032-3. [PubMed: 10599928].

29. Badparva E, Kheirandish F, Ebrahimzade F. Prevalence of intestinal parasites in Lorestan province, West of Iran. Asian Pac J Trop Dis. 2014;4:S728-32. doi:10.1016/s2222-1808(14)60716-7. 
30. von Elm E, Altman DG, Egger M, Pocock SJ, Gotzsche PC, Vandenbroucke JP, et al. [The Strengthening the Reporting of Observational Studies in Epidemiology [STROBE] statement: guidelines for reporting observational studies]. Gac Sanit. 2008;22(2):144-50. [PubMed: 18420014].

31. Asgari G, Nateghpour M, Rezaian M. Prevalence of intestinal parasites in the inhabitants of Islam-Shahr district. J School Public Health Institute Public Health Res. 2003;1(3):67-74.

32. Akhlaghi L, Shamseddin J, Meamar AR, Razmjou E, Oormazdi H. Frequency of intestinal parasites in Tehran. Iranian $J$ Parasitol. 2009;4(2):44-7.

33. Arani AS, Alaghehbandan R, Akhlaghi L, Shahi M, Lari AR. Prevalence of intestinal parasites in a population in south of Tehran, Iran. Rev Inst Med Trop Sao Paulo. 2008;50(3):145-9. [PubMed:18604414].

34. Asmar M, Ashrafi K, Amintahmasbi H, Rahmati B, Masiha A, Hadian MR. Prevalence of Intestinal Parasitic Infections in the Urban Areas of Bandar Anzali, Northern Iran. J Guilan Unive Med Sci. 2014;22(88):1825.

35. Badparva E, Pornia Y, Fallahi S. H. . Prevalence of Blastocystis hominis in Lorestan Province, West of Iran. Asian J Biol Sci. 2012;5(1):57-61.

36. Badparva E, Sadraee J, Kheirandish F, Frouzandeh M. Genetic diversity of human blastocystis isolates in khorramabad, central iran. Iran J Parasitol. 2014;9(1):44-9. [PubMed: 25642259].

37. Daryani A, Ettehad GH. Prevalence of Intestinal infestation among primary school students in Ardabil, 2003. J Ardabil Unive Med Sci. 2005;5(3):229-34.

38. Davari A, Akhlaghi L, Memar AR, Namazi MJ, Hadighi R, Tabatabaee F, et al. Frequency of intestinal parasites on mental disabilities in rehabilitation centers in Ardabil city at 2011. 2013

39. Ebadi M, Anvari MH, Rajabioun A, Dehghani AA. Parasitic infections (helminth and protozoa) in cases referring to yazd central laborator, 2002-2004. J Shahid Sadoughi Unive Med Sci. 2008;15(4):53-8.

40. Ebadi M, Behravan F, Moghaddam SHH. Prevalence of intestinal parasites and clinical manifestations in children. Iranian J Public Health. 2007;36(1 sup):1-2.

41. Falahi S, Badparva E, Nahravanian H, Chegeni SA, Ebrahimzadeh F. Prevalence of intestinal parasites in HIV+ and AIDS patients khorramabad 2006. 2007

42. Fallah E, Mahami Oskouei L, Mahami Oskouei M, Safaiyan AR. Prevalence of blastocystis hominis infection in tabriz in 2009-2010. Urmia Med J. 2014;25(2):113-8.

43. Gholami SA, Mohammadpour TR, Sharif M, Ziaei H, Euroji A, Gohardehi $S$, et al. Intestinal parasite infections in cattle breeders in rural regions of babol town during 2003. 2005

44. Haghighi A, Khorashad AS, Nazemalhosseini Mojarad E, Kazemi B, Rostami Nejad M, Rasti S. Frequency of enteric protozoan parasites among patients with gastrointestinal complaints in medical centers of Zahedan, Iran. Trans R Soc Trop Med Hyg. 2009;103(5):452-4. doi: 10.1016/j.trstmh.2008.11.004. [PubMed: 19084249].

45. Kheirandish F, Tarahi M, Haghighi A, Nazemalhosseini-Mojarad E, Kheirandish M. Prevalence of intestinal parasites in bakery workers in khorramabad, lorestan iran. Iran J Parasitol. 2011;6(4):76-83. [PubMed: 22347316].

46. Kheirandish F, Tarahi MJ, Ezatpour B. Prevalence of intestinal parasites among food handlers in Western Iran. Rev Inst Med Trop Sao Paulo. 2014;56(2):111-4. doi: 10.1590/S0036-46652014000200004. [PubMed: 24626411].

47. Khalili B, Khani MR, Taghipour S. Blastocystis hominis infection among hospitalized children due to diarrhea in hajar hospital, shahre-kord, iran. Arch Clin Infect Dis. 2012;7(2):52-5.

48. Heidari A, Rokni MB. Prevalence of intestinal parasites among children in day-care centers in Damghan-Iran. Iran J Publ Health. 2003;32(1):31-4.

49. Hazrati TK, Maleki D, Mohammadzadeh H, Zarikar B. Evaluation of prevalence of intestinal parasites in adult patients with or without gastrointestinal manifestations rederring to oncology clinic of ur- mia imam khomeini hospital. Urmia Medical Journal. 2011;22(4).

50. Hooshyar H, Bagherian T, Baghbani F. Prevalence of intestinal parasitic infections among patients referred to Kashan Reference Laboratory in 2007-2011. Jundishapur J Health Sci. 2013;5(1):18-22.

51. Jafari R, Fallah M, Darani HY, Yousefi HA, Mohaghegh MA, Latifi M, et al Prevalence of intestinal parasitic infections among rural inhabitants of Hamadan city, Iran, 2012. J Clin Microb Infec. 2014;1(2).

52. Jafari R, Sharifi F, Bagherpour B, Safari M. Prevalence of intestinal parasites in Isfahan city, central Iran, 2014. J Parasit Dis. 2014:1-4.

53. Kia EB, Hosseini M, Nilforoushan MR, Meamar AR, Rezaeian M. Study of intestinal protozoan parasites in rural inhabitants of Mazandaran province, Northern Iran. Iranian J Parasitol. 2008;3(1):21-5.

54. Kuzehkanani AB, Rezaei S, Babaei Z, Niyyati M, Hashemi S, Rezaeian M Enteric protozoan parasites in rural areas of bandar-abbas, southern iran: comparison of past and present situation. Iran J Public Health. 2011;40(1):80-5. [PubMed: 23113059].

55. Meamar AR, Rezaian M, Mohraz M, Zahabian F, Hadighi R, Kia EB A comparative analysis of intestinal parasitic infections between HIV+|AIDS patients and non-HIV infected individuals. Iranian J Parasitol. 2007;2(1):1-6.

56. Mowlavi GR, MirAhmadi H, Rezaeian M, Kia E, Rokni MB, Golestan B, et al. Prevalence of intestinal parasites in tribal parts of Khuzestan Province during 2005-07. Govaresh. 2008;12(4):219-28.

57. Mafi M, Mahmoudi M, Nahravanian H, Zahraei M, Masoumiasl H, Rahbar M, et al. Prevalence of Sporozoan and Parasitic Enteropathogen Protozoans in Patients with Gastroenteritis in Iran. Annu Res Rev Biol. 2014;4(24):3699.

58. Nasiri V, Esmailnia K, Karim G, Nasir M, Akhavan O. Intestinal parasitic infections among inhabitants of Karaj City, Tehran province, Iran in 2006-2008. Korean J Parasitol. 2009;47(3):2658. doi: 10.3347/kjp.2009.47.3.265. [PubMed:19724700].

59. Neghab M, Moosavi S, Moemenbellah-Fard MD. Prevalence of intestinal parasitic infections among catering staff of students canteens at Shiraz, southern Iran. PakJ Biol Sci. 2006;9(14):2699-703.

60. Moosavi A, Haghighi A, Mojarad EN, Zayeri F, Alebouyeh M, Khazan H et al. Genetic variability of Blastocystis sp. isolated from symptomatic and asymptomatic individuals in Iran. Parasitol Res. 2012;111(6):2311-5 doi: 10.1007/s00436-012-3085-5. [PubMed: 22948205].

61. Rostami M, Tohidi F, Sharbatkhori M, Taherkhani H, Eteraf A, Mohammadi R. The Prevalence of Intestinal Parasitic Infections in Primary School Students in Gorgan, Iran. Med Laboratory J. 2012;6(2):42-6.

62. Rostami MN, Keshavarz H, Eskandari E, Kia EB, Rezaeian M. Intestinal parasitic infections in renal transplant recipients. Iranian J Parasitol. 2007;2(3):16-23.

63. Sabati H, Lotfi $\mathrm{H}$, Mobedi I. The prevalence of intestinal parasites in children of Abu Musa. Iranian J Infectious Dis. 2004;9(27):47-51.

64. Sardarian K, Hajilooi M, Maghsood A, Moghimbeigi A, Alikhani M Withdrawn: A study of the genetic variability of blastocystis hominis isolates in hamadan, west of iran. JundishapurJ Microbiol. 2012;6(1):115 .

65. Sadeghi H, Borji H. A survey of intestinal parasites in a population in Qazvin, north of Iran. Asian Pac J Trop Dis. 2015;5(3):231-3.

66. Tappe KH, Mohammadzadeh H, Khashaveh S, Rezapour B, Barazesh A. Prevalence of intestinal parasitic infections among primary school attending students in Barandooz-Chay rural region of Urmia, West Azerbaijan province, Iran in 2008. African J Microbiol Res. 2011;5(7):78891.

67. Taherkhani H, Jadidian K, Fallah M, Vaziri S. The Frequency of Intestinal Parasites in HIV Positive PatientsAdmitted To the Disease Consultation Center in Kermanshah Province. M Laboratory J. 2007;1(2).

68. Tappeh Kh H, Mohammadzadeh H, Rahim RN, Barazesh A, Khashaveh $S$, Taherkhani H. Prevalence of Intestinal Parasitic Infections among Mentally Disabled Children and Adults of Urmia, Iran. Iran J Parasitol. 2010;5(2):60-4. [PubMed: 22347245].

69. Zali MR, Mehr AJ, Rezaian M, Meamar AR, Vaziri S, Mohraz M. Preva- 
lence of intestinal parasitic pathogens among HIV-positive individuals in Iran. Jpn J Infect Dis. 2004;57(6):268-70. [PubMed: 15623953].

70. Su FH, Chu FY, Li CY, Tang HF, Lin YS, Peng YJ, et al. Blastocystis hominis infection in long-term care facilities in Taiwan: prevalence and associated clinical factors. Parasitol Res. 2009;105(4):1007-13. doi: 10.1007/s00436-009-1509-7. [PubMed: 19488784].

71. Steinmann E, di Gallo A, Ruttimann S, Loosli ], Dubach UC. [Etiology of diarrheal diseases in immunocompetent and HIV-positive patients]. Schweiz Med Wochenschr. 1990;120(35):1253-6. [PubMed: 2218447].

72. Cheng HS, Haung ZF, Lan WH, Kuo TC, Shin JW. Epidemiology of Blastocystis Hominis and Other Intestinal Parasites in a Vietnamese Female Immigrant Population in Southern Taiwan. The Kaohsiung J Med Sci. 2006;22(4):166-70. doi:10.1016/s1607-551x(09)70302-x.

73. Torres P, Miranda JC, Flores L, Riquelme J, Franjola R, Perez J, et al. [Blastocystosis and other intestinal protozoan infections in human riverside communities of the Valdivia River basin, Chile]. Rev Inst Med Trop Sao Paulo. 1992;34(6):557-64. [PubMed:1342125].

74. Amin OM. Seasonal prevalence of intestinal parasites in the United States during 2000. Am JTrop Med Hyg. 2002;66(6):799-803. [PubMed 12224595].

75. Wu Z, Mirza H, Tan KS. Intra-subtype variation in enteroadhesion accounts for differences in epithelial barrier disruption and is associated with metronidazole resistance in Blastocystis subtype-7. PLoS Negl Trop Dis. 2014;8(5):ee2885. doi: 10.1371/journal.pntd.0002885. [PubMed: 24851944]

76. Dagci H, Kurt O, Demirel M, Ostan I, Azizi NR, Mandiracioglu A, et al. The prevalence of intestinal parasites in the province of Izmir, Turkey. Parasitol Res. 2008;103(4):839-45. doi: 10.1007/s00436-0081065-6. [PubMed: 18604653].

77. Scanlan PD. Blastocystis: past pitfalls and future perspectives. Trends Parasitol. 2012;28(8):327-34. doi: 10.1016/j.pt.2012.05.001. [PubMed:
22738855].

78. Dogruman-Al F, Yoshikawa H, Kustimur S, Balaban N. PCR-based subtyping of Blastocystis isolates from symptomatic and asymptomatic individuals in a major hospital in Ankara, Turkey. Parasitol Res. 2009;106(1):263-8. doi: 10.1007/s00436-009-1658-8. [PubMed: 19847459].

79. Abdel-Hameed DM, Hassanin OM. Proteaese activity of Blastocystis hominis subtype 3 in symptomatic and asymptomatic patients. Parasitol Res. 2011;109(2):321-7. doi: 10.1007/s00436-011-2259-x. [PubMed: 21279383].

80. Tan TC, Ong SC, Suresh KG. Genetic variability of Blastocystis sp. isolates obtained from cancer and HIV/AIDS patients. Parasitol Res. 2009;105(5):1283-6. doi: 10.1007/s00436-009-1551-5. [PubMed: 19603182].

81. Badparva E, Sadraee J, Kheirandish F. Genetic diversity of blastocystis isolated from cattle in khorramabad, iran. Jundishapur J Microbiol. 2015;8(3):ee14810. doi: 10.5812/jjm.14810. [PubMed: 25964846].

82. Forsell J, Granlund M, Stensvold CR, Clark GC, Evengard B. Subtype analysis of Blastocystis isolates in Swedish patients. Eur J Clin Microbiol Infect Dis. 2012;31(7):1689-96. doi: 10.1007/s10096-011-1416-6.

83. Arisue N, Hashimoto T, Yoshikawa H. Sequence heterogeneity of the small subunit ribosomal RNA genes among blastocystis isolates. Parasitology. 2003;126(Pt 1):1-9. [PubMed: 12613758].

84. Badparva E, Kheyrandish F, Sadraei J. Molecular study of zoonotic parasite of Blastocystis SP. in birds in Khorramabad, Lorestan provience, Iran. 2nd International and 9th National Congress of Parasitology and Parasitic Diseases of Iran (NICOPA 9) Guilan, Iran. Iran J Parasitol. 2015.

85. Badparva E, Ezatpour B, Azami M, Badparva M. First report of birds infection by intestinal parasites in Khorramabad, west Iran.JParasit Dis. 2015;39(4):720-4. doi:10.1007/s12639-014-0427-5. [PubMed: 26688641]. 